\title{
OS DILEMAS DO INDEFINIDO: UTOPIA, FLUIDEZ E SUBJETIVIDADE EM STONE, DE ADAM ROBERTS
}

\author{
André Cabral de Almeida Cardoso* \\ Universidade Federal Fluminense \\ Rio de Janeiro, BR
}

Carla de Figueiredo Portilho ${ }^{* *}$ Universidade Federal Fluminense Rio de Janeiro, BR

\begin{abstract}
Resumo:
O romance Stone, de autoria de Adam Roberts, é a narrativa em primeira pessoa de Ae, o único criminoso em uma utopia pós-humana na qual o uso da nanotecnologia levou a humanidade à plenitude. Nessa sociedade, Ae é um excluído. Um dia, porém, ele recebe uma proposta de liberdade e riqueza em troca de matar toda a população de um planeta. Ao aceitá-la, Ae deve tentar cumprir sua missão ao mesmo tempo em que se questiona e investiga quem o teria contratado. No conflito entre esse indivíduo desviante e a utopia, Stone examina os próprios limites dessa utopia, apoiada na ideia de fluxo e indefinição, e dos modelos de subjetividade que ela cria. A noção de utopia como um projeto social bem definido é trocada pela imagem de corpos utópicos, influenciados por tecnologias que põem em questão as definições de humano e pós-humano. Nessa rede de tensões e indefinições, levanta-se a possibilidade de que o indivíduo marginalizado e sociopata seria o único capaz de examinar de forma profunda a realidade num mundo anestesiado pelo conforto.
\end{abstract}

Palavras-chave: Adam Roberts, utopia, identidade, fluidez, pós-humano, detetive metafísico.

\section{THE DILEMMAS OF INDEFINITENESS: UTOPIA, FLUIDITY AND SUBJECTIVITY IN STONE, BY ADAM ROBERTS}

\begin{abstract}
:
Ae, the narrator-protagonist of the novel Stone, by Adam Roberts, is the only criminal in a post-human utopian society in which the use of nanotechnology has allowed humanity to reach its plenitude. Isolated from the rest of society, one day Ae is offered freedom and wealth if he agrees to kill the population of a whole planet. After accepting this offer, Ae must try to fulfil his mission at the same time that he questions himself and tries to discover who his employers are. In developing the conflict between this deviant individual and the utopia in which he lives, Stone examines the limits of the utopia itself, which is based on the idea of flux and indefiniteness. The novel also explores the models of subjectivity created in the context of this utopia. The notion of utopia as a well-defined social project is replaced by the image of utopian bodies, influenced by technologies that challenge the definitions of the human and of the post-human. In establishing this network of tensions and indefiniteness, the novel offers the possibility that the marginalized sociopath might be the only one capable of examining in depth the reality of a world anesthetized by its own comfort.
\end{abstract}

Keywords: Adam Roberts, utopia, identity, fluidity, post-human, metaphysical detective.

${ }^{*}$ Professor Adjunto de Literaturas de Língua Inglesa da Universidade Federal Fluminense (UFF). Atualmente pesquisa a representação da utopia e da distopia na ficção científica, além da construção da noção de identidade na literatura contemporânea. E-mail: andrecac@id.uff.br.

${ }^{* *}$ Professora Adjunta da Universidade Federal Fluminense (UFF) e membro do grupo de pesquisa "Habitando Modernidades: (crise da) memória, hierarquias opressivas, utopias possíveis” (CNPq). Sua experiência no campo de Letras dá ênfase à Literatura Comparada e trabalha principalmente com estudos culturais, literatura de crimes, romance policial, narrativas contra-hegemônicas e memória. Seu e-mail é carla_portilho@id.uff.br. 


\section{Física quântica, fluidez e utopia}

O romance Stone, do autor britânico Adam Roberts, publicado em 2002, é uma obra de ficção científica narrada em primeira pessoa por Ae, o único assassino de $\mathrm{t}^{\prime} \mathrm{T}$, uma civilização aparentemente perfeita na qual o uso disseminado da nanotecnologia levou à satisfação plena de todas as necessidades humanas, eliminando a fome, as doenças e quaisquer outros desequilíbrios que antes afligiam a humanidade. Nessa civilização utópica, o crime praticamente inexiste, e matar alguém é uma missão quase impossível devido à proteção oferecida pelas nanomáquinas que "habitam" o corpo, responsáveis por eliminar qualquer dor ou desconforto e preservar a vida dos cidadãos de t'T acima de tudo.

O livro se abre com duas epígrafes dos físicos Niels Böhr e Werner Heisenberg que trazem à tona o tema da incompreensão ao apontar para a dificuldade (ou a impossibilidade) de se entender os fenômenos quânticos. Uma terceira epígrafe, retirada de Otelo, ato IV, cena 1 ("My heart is turned to Stone/I strike it and it hurts my hand") remete ao título do livro e à insensibilidade de um coração endurecido pelo ciúme; isolado do contexto original da peça, porém, esse trecho remete também a outra forma de incompreensão: a do sujeito que olha para dentro de si mesmo e não consegue se entender, uma vez que seu coração se tornou um objeto denso e opaco, que fere quando se tenta tocá-lo. A essas epígrafes segue-se uma breve introdução à física quântica, retirada do livro Quanta: Essays on Quantum Physics.1 Aqui a incompreensão novamente vem à tona, desta vez relacionada à indeterminação dos fenômenos quânticos, à impossibilidade de se decidir, ao mesmo tempo, onde se encontra um átomo e a velocidade com que ele se desloca. A discussão em torno da física quântica parece ter pouca relação com o enredo e com o que seriam as preocupações básicas da narrativa: a psicologia de um sujeito aberrante e sua relação com a dinâmica de uma sociedade ideal. No entanto, ela levanta questões que são essenciais para a noção de utopia delineada no romance e para a imagem de individualidade construída na narrativa através da figura de seu protagonista/narrador.

Num primeiro nível, mais superficial, tanto as epígrafes quanto o texto atribuído a Kurt Soldan cumprem a função de estabelecer os princípios básicos que fornecem o fundamento científico ou pseudocientífico da narrativa. A sociedade utópica de t'T é uma confederação de planetas de culturas diferentes, mas unidos por uma língua comum, distribuídos por uma região do espaço que se estende por milhares de anos-luz. Sendo assim, para que essa sociedade possa existir, ela depende de uma forma de deslocamento ou comunicação mais rápida do que a luz. Em Stone, esse tipo de deslocamento está calcado nas propriedades das partículas subatômicas estudadas pela física quântica. Segundo Ae, os elétrons que giram em torno do núcleo de um átomo se distribuem em órbitas diferentes, mas podem saltar de uma órbita para outra quando a quantidade de energia injetada no sistema se modifica. Ao fazer isso, o elétron se desloca no espaço e, apesar de a distância percorrida nesse "salto" ser mínima, o deslocamento se dá de forma instantânea. A tecnologia de viagem espacial desenvolvida em t'T extrapola essa propriedade das partículas subatômicas para um corpo maior, somando trilhões de saltos minúsculos no nível subatômico para cobrir as gigantescas distâncias entre os planetas, numa velocidade milhares de vezes superior à da luz, numa espécie de paradoxo de Zenão invertido. Esse deslocamento no espaço é regulado por processadores que coordenam os saltos quânticos das partículas que compõem um corpo, e a velocidade atingida depende apenas da rapidez com que esses processadores podem fazer os cálculos necessários. Quanto maior o corpo a ser deslocado, maior será a quantidade de cálculos exigida para que a viagem se realize; sendo assim, o deslocamento de corpos muito grandes pelo espaço interestelar é impraticável, pois a quantidade de cálculos exigida tornaria a viagem lenta demais. Além disso, só seres dotados de consciência podem realizar esse tipo de viagem, pois é necessária a presença de um observador para fixar o deslocamento das partículas no nível quântico, que de outra forma permaneceria indefinido.

Outro elemento definidor da utopia traçada em Stone também está relacionado às propriedades da física quântica evocadas nas primeiras páginas do romance. As nanomáquinas que garantem o bem-estar dos habitantes de t'T são formadas por apenas alguns átomos, mas, trabalhando em conjunto, têm a capacidade de 
solucionar problemas e são dotadas de inteligência, características imprescindíveis para sua tarefa de monitorar constantemente os corpos que habitam e de efetuar reparos imediatos sempre que necessário. Presentes em todos os corpos, e mesmo no ar que os circunda, elas são "invisíveis" e "ubíquas", como Ae observa. Pode-se dizer que elas formam o tecido que une a sociedade utópica como um todo, e o nome pelo qual são chamadas, dotTech, parece remeter à internet, evocando no leitor a imagem de uma vasta rede de comunicação. Perpassando todos os corpos, elas formam a imagem fantasmagórica de um vasto corpo virtual e, nas últimas páginas do romance, torna-se claro que as nanomáquinas formam também uma consciência - ou várias consciências interconectadas - com a qual Ae dialoga. A tensão entre o infinitamente grande e o infinitamente pequeno, já presente no método de viagem espacial da utopia (em que trilhões de microscópicos saltos quânticos tornam possível cobrir distâncias gigantescas), se reproduz nas nanomáquinas. Tomadas em conjunto, elas formam uma entidade vasta, mas individualmente são microscópicas, habitando o mundo do atômico e do subatômico, e, portanto, existindo de acordo com o princípio da incerteza quântica. Isso significa que elas permanecem em um estado de fluxo, fixando-se apenas quando a vontade ou as necessidades de seu hospedeiro, expressas através de sua consciência ou de seu corpo, assim o exigem. Pode-se dizer, então, que toda a utopia delineada em Stone está calcada num princípio de incerteza, pois é a partir desse princípio que funcionam seus dois esteios principais - a viagem em velocidades superiores à da luz e a nanotecnologia.

A física quântica, portanto, age como elemento estruturador do mundo ficcional criado na narrativa. No entanto, como Gérard Klein indica, o texto de ficção científica lida com a ciência apenas de forma indireta. A ficção científica, na verdade, se apoia nas imagens e representações derivadas da ciência que são absorvidas pelo conhecimento público e tornam-se parte do imaginário popular. Essas imagens são trabalhadas pelo autor da narrativa, mas, antes disso, são contaminadas não só por outras imagens e representações, mas também por conceitos ideológicos, filosóficos e mesmo religiosos que antecedem a observação científica que lhes deu origem (KLEIN, 2001, p.119-20). Sendo assim, o discurso científico não serve tanto como fundamento "real" para a narrativa de ficção científica, quanto como um potencial metafórico ou alegórico do qual essa narrativa se apropria. O caso de Stone é particularmente claro nesse sentido: os princípios da física quântica, filtrados por sua representação popular, são tomados como elementos alegóricos que desenvolvem alguns dos temas centrais da narrativa, incluindo a delineação de identidades desviantes ou utópicas que estruturam a visão do pós-humano presente no romance.

Desse modo, o princípio da incerteza quântica, segundo o qual a mesma partícula subatômica ocupa várias posições diferentes simultaneamente, até que a observação a fixe em uma, e apenas uma, dessas posições, "contamina" outros elementos da narrativa, que também ocupam simultaneamente posições opostas. Segundo o narrador do romance, o modo de vida na utopia de Stone é determinado pela viagem interestelar, ou seja, por uma ideia de movimento que reproduz a fluidez das partículas subatômicas. No entanto, apesar dos mundos de $\mathrm{t}^{\prime} \mathrm{T}$ estarem espalhados e não apresentarem uma estrutura de poder centralizada e rígida, a utopia como um todo possui fronteiras claramente delimitadas no espaço e no tempo: a viagem em velocidades superiores à da luz só é possível dentro de uma região específica do espaço, que está encolhendo gradualmente. Ao mesmo tempo em que persegue a diversidade (não só a diversidade cultural, mas também a diversidade física dos corpos adaptados pela nanotecnologia para assumir aspectos e funções diferentes, muitos deles se afastando do fenótipo humano), essa utopia também estabelece uma clara distinção entre seus membros e outras sociedades que vivem para além de suas fronteiras e que são consideradas bárbaras por rejeitarem a nanotecnologia e se aterem a uma configuração estritamente humana. Mesmo na imagem da viagem interestelar de Stone, tensões semelhantes se fazem presentes. A viagem é uma forma de conexão entre os mundos de t'T, organizados numa espécie de rede; no entanto, ainda que motivadas pela busca de contato com outras pessoas, por um intenso impulso de socialização, as viagens se dão no mais absoluto isolamento: cada indivíduo avança sozinho pelo espaço, envolvido 
numa camada de espuma endurecida que o isola dos rigores do vácuo, mas também de todo estímulo sensorial externo.

Mas não é só na imagem do deslocamento que a fluidez se manifesta como o fundamento dessa utopia. Ela também está presente nos corpos de seus habitantes, que podem se adaptar e se modificar de acordo com o seu desejo, e, portanto, não permanecem fixos. Em "Utopia with No Topos", Zygmunt Bauman estabelece uma correlação entre utopia e a formação do Estadonação moderno através da noção de soberania. Tanto na utopia clássica quanto nas definições tradicionais do Estado moderno, a soberania está relacionada à territorialidade; segundo Bauman, o soberano é aquele que detém o poder de admitir ou não um indivíduo no domínio da lei, e todos aqueles que vivem dentro de seu território estão submetidos a esse poder. Dentro do território, cada indivíduo está alocado a seu lugar de direito, e aqueles que são excluídos pelo poder do soberano se veem destituídos de qualquer direito, vivendo, nas palavras de Bauman (2003, p.13), uma vida “'nua, puramente corporal" (tradução livre). A utopia clássica seria uma forma de soberania territorializada da mesma forma, e nela é possível encontrar mecanismos de exclusão semelhantes. Na utopia de Stone, porém, esse território é sobretudo o corpo.

\section{O corpo paradoxal do assassino}

Ae é um assassino, que descreve a si mesmo como "um homem mau", ao contar, em flashback, sua história a uma pedra (de onde advém uma das razões para o título do romance, Stone):

I am a bad man, I've done some bad things. I beg your pardon, stone, in telling you these things (do you like that politeness? You're an ancient object, and I've got a whole store of ancient cultural habits to deploy if I feel like it). I am a bad man. I still think of myself as a man, in fact, although there's little biological evidence for that fact. When the nanotechnology abandoned my body the default biological settings reasserted themselves. I had liked being a man, in fact. I'd been a man for so long I'd acquired the mental habit of calling myself male, of thinking it at a deep level. I still think that way, even though my male genitalia have long since shrunken and wizened like drying fruit, grapes turning to raisins and finally shrinking to nothing at all. (ROBERTS, 2002, p. 1)

Expulso da utopia, Ae vive isolado em uma prisão de segurança máxima, um mundo artificial construído no interior do plasma de uma estrela, de onde acredita ser impossível escapar. No entanto, sua verdadeira punição - que ele chama de "execução", pois a encara como uma morte - é a retirada da nanotecnologia de seu corpo. Ele sofre os tormentos de uma vida sem dotTech - contrai doenças e sente frio, cansaço, solidão e oscilações de humor. Exceto por determinados povos de fora da região de t'T, que não usam a nanotecnologia por razões ideológicas, Ae é o único ser humano que não traz essa tecnologia no corpo. Destituído das nanomáquinas que lhe conferiam uma condição pós-humana e, portanto, reintegrado ao que os leitores comumente associariam à humanidade, Ae paradoxalmente se vê privado do que, na sua opinião, o define como um ser humano.

É esse ato que o separa definitivamente do resto da utopia. Agora, despido da nanotecnologia, Ae está de fato nu: "Here I am, naked and alone", diz ele na prisão (ROBERTS, 2002, p.22). Além disso, sua existência também se torna "puramente corporal". A materialidade de seu corpo é marcada com insistência na narrativa a partir do momento em que a dotTech lhe é extraída. Nesse ponto, entra em cena outro tipo de fluidez, uma fluidez mais concreta, por assim dizer, e excessiva. É assim que Ae descreve a saída da nanotecnologia de seu corpo:

I coughed, wept. The hunger to die, as sharp and tangy as a physical hunger, overwhelmed me again. But I stayed alive. Fluid poured from me; vomit from my mouth, tears and rheum from my eyes, mucus from my nose, urine from between my legs. Even my pores wept myriad little dots of blood. (ROBERTS, 2002, p.9-10)

Trata-se, é claro, do espetáculo de um corpo sofredor, mas sobretudo de um corpo sujo, repugnante, degradado ao ser reduzido à representação externali- 
zada de seus processos fisiológicos mais básicos. Tratase também de um corpo cujas fronteiras são apagadas, que põe para fora aquilo que deveria manter guardado dentro de si - um corpo abjeto, na concepção de Julia Kristeva (1982, p.3-4), principalmente se levarmos em conta que esse apagamento de fronteiras se dá basicamente através da exibição de fluidos corporais, que provocam nojo ao lembrarem a morte e que, portanto, devem ser expelidos para preservar a coerência do ego. No entanto, esse próprio excesso chama atenção para a presença inescapável do corpo, que, mesmo ameaçado de desagregação, agora tem a materialidade e a opacidade da pedra que dá título ao romance. A pedra já tinha sido mencionada no texto introdutório atribuído a Kurt Soldan como exemplo de corpo oposto ao mundo quântico, um corpo mensurável que obedece às leis da física newtoniana e cujo movimento, quando arremessado no espaço, é previsível. Ae vê a pedra como a única criatura objetiva de seu mundo (ROBERTS, 2002, p.21), um ponto imóvel e silencioso (idem, p.38), mas com o qual, de qualquer forma, ele tenta estabelecer algum tipo de comunicação.

Ao menos num primeiro momento, portanto, o corpo reduzido à sua materialidade se apresenta em contraste com o corpo fluido da utopia, representado não só pelos corpos pós-humanos em constante mutação, mas também pelo corpo virtual da dotTech. De um lado, os objetos regidos pela física newtoniana; de outro, os objetos regidos pela física quântica. O próprio Ae contrasta seu corpo "degradado", que agora sangra, sente fraqueza e fica adoentado, com o corpo regulado pela dotTech, que torna tudo "suave e puro" (ROBERTS, 2002, p.8; tradução livre).

No texto "Le corps utopique", Foucault argumenta que o corpo físico é o oposto da utopia, pois é um lugar absoluto, do qual não se pode escapar. A utopia teria justamente o objetivo de apagar o corpo; ela seria um lugar fora de todo lugar, onde seria possível ter um corpo "sem corpo, um corpo que será belo, límpido, transparente, luminoso, veloz, colossal na sua potência, infinito na sua duração, livre, invisível, protegido, sempre transfigurado" (FOUCAULT, 2009, p.10; tradução livre). A utopia de Stone está centrada num sonho desse tipo, não só ao oferecer o corpo "suave e puro" dese- jado por Ae, mas também ao abrir a possibilidade da transformação permanente. Não é à toa que a estrutura social dessa utopia nunca nos é dada por completo. Calcada na satisfação imediata de desejos individuais, ela é um exemplo daquilo que Lyman Tower Sargent considera uma utopia de gratificação sensual, simplicidade e abundância, encontrada nos mitos de uma idade de ouro ou do paraíso terrestre, em que o conforto perfeito é atingido sem o esforço humano (em Stone, o trabalho humano não parece ser um fator; há apenas fruição, e tudo depende da dotTech, que surge quase como um presente divino ou uma força natural) - nas palavras de Sargent (1994, p.10), esse tipo de utopia seria uma utopia corporal.

Stone, então, giraria em torno da noção de um corpo utópico límpido e sempre transfigurado sugerida por Foucault, ao qual estaria associada uma subjetividade igualmente fluida. Mas seria esse o único corpo utópico possível? Algumas páginas mais adiante em seu texto, Foucault dá uma reviravolta em seu argumento e propõe que o corpo físico também possui lugares sem lugar, lugares ocultos e misteriosos, invisíveis, que quebram as fronteiras entre o interno e o externo: a cabeça, por exemplo, por onde entram as coisas do mundo, ao mesmo tempo em que elas permanecem do lado de fora. Surge, então, a imagem de um corpo que é "penetrável e opaco, corpo aberto e fechado"; um corpo utópico, ligeiro, transparente e imponderável (FOUCAULT, 2009, p.13; tradução livre). Para Foucault, porém, ao adoecer, o corpo volta a ser simples coisa, e seus aspectos utópicos são bloqueados. Em Stone, no entanto, se dá justamente o contrário: é ao adoecer que o corpo de Ae libera todo o seu potencial utópico, ainda que, paradoxalmente, essa condição utópica seja vivida como dor e sofrimento. Como já vimos, ao perder a dotTech, o corpo de Ae tem suas fronteiras desestabilizadas e tornase paradoxal, ao mesmo tempo opaco e externalizando seus processos fisiológicos; fixo, mas representado por fluidos. Ao se tornar abjeto, o corpo de Ae perturba a própria noção de uma identidade centralizada e fixa, e se opõe a qualquer ordenação. Uma função do abjeto, segundo Kristeva, é justamente desestabilizar fronteiras e limites. Não é à toa que esse corpo desregulamentado pertence a um assassino: para Kristeva (1982, p.4), 
o crime - e principalmente o crime premeditado - está associado ao abjeto, pois revela a fragilidade da lei como elemento garantidor da ordem.

\section{O crime e o assassino-detetive}

Logo no início da narrativa, Ae relata que um dia sua rotina de prisioneiro foi quebrada por uma voz lhe falando em sua cabeça, oferecendo liberdade e riqueza em pagamento por cumprir uma única missão para os seus libertadores: exterminar os 60 milhões de habitantes de um planeta, sem destruir a estrutura física do planeta em si. Sendo o único assassino conhecido pela humanidade, Ae parece a pessoa certa para o "trabalho", embora não consiga conceber como seria possível levar a cabo um assassinato em massa de tal magnitude em um mundo protegido pela dotTech. A voz, que por vezes ele acredita ser uma inteligência artificial implantada em seu cérebro, e por outras crê ser uma prova irrefutável de sua loucura, lhe assegura que o mandante desconhecido e misterioso se compromete não apenas a libertá-lo de sua estrela-prisão para que possa cumprir o encargo, mas também a dar-lhe as instruções necessárias para tal. Ae é confrontado com a necessidade de escolher entre matar a população do planeta e assim reconquistar sua liberdade, ou recusar a tarefa e seguir prisioneiro. Embora, seja o que o senso comum rotula como um sociopata, demonstrando desprezo pelas regras e obrigações sociais e falta de consideração pelos sentimentos alheios, Ae reluta por um breve momento. No entanto, ante a alternativa possível, qual seja, manter o estado de coisas e permanecer encarcerado na prisão-estrela, ele aceita a proposta.

Aceitar a proposta, entretanto, não se mostra uma escolha simples. Em um primeiro momento, Ae se ocupa das tarefas necessárias para a sua fuga, orientado pela inteligência artificial (I.A.), que o instrui a ingerir determinados tipos de alimentos e a praticar determinados exercícios de modo a se preparar para a jornada através do plasma da estrela. A própria I.A. lhe dá orientações quanto ao modo de emular a capa de espuma necessária para as viagens em velocidades superiores à da luz. Ae atravessa todo o plasma da estrela envolto nesse casulo protetor, até ser resgatado por uma nave comandada por Agifo3acca, membro da civilização Wheah, que não utiliza a dotTech (o que leva Ae a pensar que rebeldes Wheah poderiam estar por trás da decisão de assassinar a população do planeta, uma interessante pista falsa...) Na nave de Agifo3acca, Ae se recupera do desgaste da fuga e aguarda instruções a respeito de como cumprir a sua tarefa.

Embora nunca declare explicitamente se tem dúvidas acerca da decisão que tomou, nem leve o leitor a crer que não cumprirá a tarefa, Ae, uma vez libertado da prisão-estrela, inicia uma sequência interminável de viagens pelos diversos mundos de $\mathrm{t}^{\prime} \mathrm{T}$, e sua procrastinação sugere uma certa relutância em cumprir a missão. Ainda que constantemente ameaçado pela I.A., que lhe relembra a todo instante que o descumprimento do acordo o levará de volta à prisão-estrela, Ae se questiona intensamente quanto às razões do mandante do crime para almejar o assassinato em massa, e não consegue frear o impulso de investigar tanto a identidade do mandante quanto a sua motivação.

$\mathrm{O}$ questionamento que Ae empreende o ressignifica como personagem. A princípio, trata-se apenas de um sociopata condenado à morte, contratado por um desconhecido para cometer um crime hediondo de proporções planetárias; ao se imbuir da função de detetive e buscar descobrir o mandante do crime e sua motivação, Ae impulsiona a narrativa na direção de um enigma policial e torna-se, a um só tempo, o executante do crime e também o investigador. Essa superposição de funções remete novamente à fluidez apresentada pelo personagem, e é mais um exemplo da convivência simultânea de elementos opostos dentro da narrativa.

Em seu website, o próprio Adam Roberts descreve Stone como um tipo de romance policial:

It's a sort of whodunit, set in a far-future interstellar Utopia. The novel's narrator, a broken-down holy-fool and sociopath, is employed to murder the population of an entire planet, and whilst accepting this commission tries to discover who is behind the request; in other words he is both the whodunit "murderer" (in that he commits the crime) and the whodunit "detective" (in that he is trying to uncover who is really behind the crime). (ROBERTS, s/d) 
Levando-se em conta o papel duplo de Ae como assassino e detetive a um só tempo, é interessante considerar dois conceitos relacionados ao estudo da ficção policial: o conceito de detetive metafísico (HOLQUIST, 1971), derivado do conceito de história de detetive metafísica (HAYCRAFT, 1941), e o conceito de detetive ontológico (GOMEL, 1995).

A ficção policial metafísica pode ser definida como aquela que se encerra com perguntas em vez de respostas, na qual o detetive não apenas falha na resolução do crime, mas também se confronta com mistérios relacionados a questões de interpretação e identidade, empreendendo, nas palavras de Patricia Merivale (1999, p.1), "um profundo questionamento sobre narrativa, interpretação, subjetividade, a natureza da realidade e os limites do conhecimento" (tradução livre). Em termos bastante breves, pode-se dizer que o detetive metafísico investiga a si próprio, e sua inabilidade ao interpretar o mistério proposto representa a sua tentativa frustrada de compreender o mundo. Dessa forma, as histórias terminam com novas questões, que, se resolvidas, levam ainda a outras questões, e assim por diante - a procura do detetive por respostas é subjetiva, e não alcança qualquer resposta objetiva, mas apenas o impulsiona a uma nova busca, também subjetiva, e assim sucessivamente. Citando Alain Robbe-Grillet, que afirma que a "objetividade no sentido comum da palavra - total impessoalidade de observação - é obviamente uma ilusão" (tradução livre), Todd Natti (2004, p.1) conclui que não há respostas objetivas no texto porque a objetividade não existe. Em 1995, Elana Gomel propôs um desdobramento do conceito de detetive metafísico e cunhou o termo detetive ontológico para se referir aos protagonistas de narrativas (muito comuns na ficção científica, mas não necessariamente restritas ao gênero) nas quais o objeto de investigação é o próprio mundo onde a ação transcorre - o mundo em si se torna um mistério a ser resolvido, um segredo a ser desvendado. Nas palavras de Gomel (1995, p.346), "é o corpo do mundo, por assim dizer, mais do que o corpo na biblioteca, que se embebe de todas as energias misteriosas e malévolas atribuídas ao cadáver na ficção policial" (tradução livre). Dessa forma, vê-se que os dois conceitos estão interligados e são complementares: enquanto o detetive metafísico investiga a si próprio, o detetive ontológico investiga o mundo em que vive - e poderíamos dizer que, em Stone, o corpo misterioso de Ae e, mais ainda, o corpo virtual da dotTech são representações concretas dessa subjetividade e desse "corpo do mundo" a serem desvendados, mas cujo enigma nunca chega a ser completamente solucionado.

Com o propósito explícito de receber a informação necessária para desempenhar a tarefa que lhe foi designada, e a motivação subliminar de descobrir o mandante do crime, Ae parte em uma jornada que o leva a diversos mundos de t'T, em uma espécie de viagem turística interestelar, ao longo da qual o leitor tem inúmeras oportunidades de vê-lo atuando em plena ambiguidade: Ae alterna momentos em que escolhe agir como assassino com outros em que o ímpeto investigativo do detetive prepondera. Em duas ocasiões, Ae opta por matar, embora seja bem-sucedido apenas na primeira; em ambos os casos as vítimas são mulheres com as quais se envolveu, por escolha própria ou não, e que descobriram sua condição de criminoso foragido da prisão-estrela. A cena em que o assassinato é consumado descreve com crueza de detalhes o quanto a tarefa de matar um corpo protegido pela dotTech pode ser difícil:

The dumb flesh seemed to be resisting me. It was as if the whole universe were taunting me. With several huge blows, one or two of which seemed to go astray, I finally cut the head free from the body. [...] The dotTech had done a clever thing. This is how smart it is, the nanotechnology: it had realized that the head was severed from the body and it had closed down the blood and lymph vessels to preserve the precious blood in Enkida's brain where it would keep her alive, feeding a small quantity of oxygen to it, that the machines themselves absorbed through the skin. But of course it would not be able to keep her alive indefinitely, separated from her body as she now was. (ROBERTS, 2002, p.86-87)

A cena do assassinato mostra a Ae que a sensação de matar continua a lhe proporcionar prazer, reforçando a sua condição de assassino e enfatizando para o leitor que não há uma mudança de caráter no protagonista. Ae não deixa de ser um assassino para se tornar 
detetive, mas ocupa ambas as posições ao mesmo tempo. Seu objeto de investigação não é o crime em si, por maior que seja a proporção que este possa tomar. Sua investigação diz respeito a si próprio - não aos motivos que poderiam tê-lo levado aos assassinatos e outras indagações de natureza racional que busquem explicar causas e consequências para o crime, mas simplesmente ao papel específico que um assassino como ele desempenha no universo utópico de t'T, onde não parece existir motivação ou lugar para o crime. Como o detetive metafísico, Ae precisa buscar compreender a si próprio e, como o detetive ontológico, precisa estender essa busca de compreensão ao mundo em que vive, de modo a tentar descobrir em que circunstâncias e a quem um assassino seria útil. Sua mente se perde em elocubrações e fantasias acerca das possíveis motivações para um crime tão "grandioso" - ele é levado a pensar em guerras e revoltas, em ataques vindos das civilizações que vivem fora da região de t'T.

Ao longo do seu período de relutância e procrastinação, Ae se envolve amorosamente com Klabier, uma mulher que vem a ser membro da polícia interestelar e que desconfia que Ae seja o fugitivo da prisão-estrela. Ao ser desmascarado, Ae tenta mais uma vez resolver a questão por meio de um assassinato, empurrando Klabier do alto de um arranha-céu. Sem saber se ela morreu ou se a dotTech em seu organismo foi capaz de salvá-la, Ae foge da cena do crime e finalmente começa a seguir as instruções dadas pela I.A. para o cumprimento de sua missão. Ele viaja para o planeta indicado pela I.A., onde recebe uma espécie de pendrive contendo informações sobre os buracos negros do espaço e a tecnologia que pode ser utilizada para criá-los - essa é a tecnologia que ele deve usar para destruir a atmosfera do seu planeta-alvo, matando por asfixia seus $60 \mathrm{mi}-$ lhões de habitantes.

Ae cumpre então a sua parte no acordo. Uma vez mortos os 60 milhões de habitantes do planeta, ele mais uma vez se refugia na nave de Agifo3acca, e exige uma explicação. Em seus devaneios, Ae acredita que Agifo3acca e os Wheah podem estar por trás do genocídio e tentam matá-lo, levando-o a fugir. Sozinho na nave e imerso em delírios acerca do ocorrido, Ae finalmente começa a perceber que não há elementos externos co- mandando o crime. Seus "empregadores" revelam que são a rede de inteligência formada pela dotTech.

A consciência da enormidade de seus crimes se abate sobre Ae nos momentos imediatamente posteriores ao assassinato e à revelação da dotTech. Ele não tenta fugir, ainda que a liberdade tenha sido o pagamento mais almejado quando recebeu a oferta. Avisada por Agifo3acca, logo a polícia interestelar chega para recapturá-lo. Mais uma vez, Ae assume a dualidade culpado/ punidor. Como assassino, cumpre a tarefa de exterminar a população do planeta; entretanto, ao invés de usufruir do prêmio recebido pelo assassinato, ou seja, a reconquista da sua liberdade, ele se deixa capturar e é levado de volta à prisão, de modo que a opção de entregar-se torna-se uma espécie de cumprimento do dever de detetive. Nas palavras de Adam Roberts (s/d), “[...] em retrospecto, me dou conta de que o livro é obviamente sobre a escolha, sobre a redução ou a abertura de possibilidades" (tradução livre).

\section{Controle e indefinição}

De fato, assim como a dualidade detetive/criminoso se mantém constante ao longo de todo o romance, um dos impulsos da narrativa parece ser justamente manter em aberto o horizonte das possibilidades, colocado em permanente tensão com o fechamento imposto pelas escolhas. O crime em Stone de fato é abjeto na concepção de Kristeva: como o corpo utópico de Foucault, ele se opõe ao significado e é essencialmente indefinível.

Ao desequilibrar a distinção entre o que é interno e o que é externo, a enfermidade abre o corpo de Ae para o mundo. Na verdade, o ambiente penetra e perpassa o corpo de Ae através das feridas e doenças que lhe impõe: cortes e raladuras ao esbarrar em certos objetos, infecções, invasão de parasitas. Ao mesmo tempo, Ae passa a prestar uma enorme atenção a suas sensações físicas, que ele descreve em detalhes, e é através delas que ele estabelece contato com a realidade à sua volta $\mathrm{e}$ a interpreta. A sensibilidade de Ae parece se intensificar com a ausência da dotTech, em contraste com a sensibilidade aparentemente amortecida dos habitantes de $\mathrm{t}^{\prime} \mathrm{T}$. Estes não recebem parte dos estímulos impostos pelo 
ambiente, já que a dor e qualquer sensação desconfortável são imediatamente suprimidas pela nanotecnologia que eles trazem dentro de si. Ao falar da coceira que agora sente, Ae afirma que a pedra e os membros da utopia têm em comum o fato de não conhecerem essa sensação. Os seres pós-humanos protegidos pela dotTech e a pedra, portanto, compartilham a mesma insensibilidade e são corpos fechados para o mundo.

Essa forma de representar o corpo de Ae seria uma imagem concreta da condição do detetive ontológico. Com a sua sensibilidade aguçada pela falta da dotTech, Ae torna-se, como um todo, uma espécie de máquina de investigar o mundo, em oposição aos habitantes da utopia, que são, de certo modo, anestesiados pela presença da dotTech em seus organismos e ocupariam, portanto, mais a posição de objetos da investigação do que a de sujeitos propriamente ditos. A alienação dos habitantes de t'T é um aspecto frisado com certa insistência ao longo de todo o romance, uma vez que eles não são dados a questionar sua condição, e seu contato com o ambiente que os cerca é sempre filtrado pela nanotecnologia. A função de sujeito é exercida por Ae, não por acaso, um sociopata que tende a ver todos os outros como objetos. Nesse sentido, um dos pontos interessantes da narrativa de Stone é colocar o sociopata como o único capaz de funcionar como um detetive ontológico, ou seja, aquele capaz de investigar o seu mundo.

As sensações de Ae também tornam o seu corpo transparente, já que suas emoções se manifestam imediatamente em reações corporais. Depois de um momento de prazer ao matar a primeira mulher que o reconheceu, ele corre cegamente, bate os dentes, chora, sua perturbação (que não configura um arrependimento) intensificada pelo fato de a dotTech não estar mais presente em seu corpo para regular sua descarga hormonal. De fato, sem a presença da dotTech, o corpo de Ae passa a ser uma expressão física do seu estado de exceção. Ele contrasta com os corpos perfeitamente regulados e normatizados dos habitantes da utopia. Apesar de sua aparente variabilidade, esses corpos pós-humanos, em geral, apresentam modificações puramente superficiais, de caráter estético e sem grande aplicação prática. Algumas dessas modificações visam a aumentar o prazer sensual do corpo, e costumam ser apre- sentadas na narrativa como elementos bizarros, como crescer narinas mais largas para criar uma nova zona erógena, ou bolsas de sustentação para descer um rio como uma barca, pelo simples prazer de sentir o fluxo da correnteza.

Os corpos muitas vezes grotescos dos habitantes de t'T podem ser vistos como componentes satíricos do texto, e sua interpretação é instável, pois eles parecem oscilar entre a proposição séria de um ideal a ser almejado e a crítica de caráter cômico a certos comportamentos da sociedade contemporânea. Por um lado, a ênfase dada ao prazer sensual e à perversão sexual (narinas se tornam órgãos sexuais) aponta para a erotização do corpo como um todo e à busca do prazer como um fim em si mesmo, aspectos que Marcuse (2007, p.5355 ) identifica com a utopia por se oporem ao princípio de produtividade e utilitarismo da sociedade moderna. Por outro lado, as transformações passageiras e superficiais por que passam esses corpos reproduzem uma lógica de consumo em que objetos são adquiridos, rapidamente usufruídos e depois abandonados em troca de outras mercadorias que oferecem um novo estímulo. Para Sennett, há um elemento de liberdade nesse desapego estimulado pelo consumismo. No entanto, esse desapego só é possível porque a maioria dos objetos de consumo é padronizada, apresentando diferenças puramente superficiais que servem apenas para ocultar uma homogeneização subjacente (SENNETT, 2006, locs. 958, 1003-06). Se as constantes reconfigurações sofridas pelos corpos dos habitantes de t'T são objetos de consumo desse tipo, elas de fato trazem consigo uma sensação de liberdade, ainda mais se levarmos em conta que elas não têm nenhum custo econômico e estão desligadas da produção e de todos os conflitos que esta acarreta. Entretanto, sua superficialidade é uma garantia de que cada indivíduo permanece perfeitamente integrado à ordem vigente. Um dos pontos mais satíricos do romance aborda justamente a existência de grupos "dissidentes" que discutem política como um puro exercício de distração e que exibem um total desconhecimento daquilo que é verdadeiramente outro: as comunidades que existem fora da utopia e que optaram por não utilizar a nanotecnologia em seus corpos. As transformações físicas são excessos que 
recobrem a uniformidade do controle: controle das sensações e das reações físicas do corpo, que nunca se mostra realmente transgressor.

A exceção é o corpo adoecido e incontrolado de Ae, que o marca como desviante e que provoca repulsa. Como o próprio Ae observa, não há nada mais transgressor do que a doença numa cultura de saúde perfeita. Sua própria sexualidade se torna mais transgressora com a ausência da dotTech. Como vimos anteriormente, Ae é biologicamente uma mulher. No entanto, sua tendência sexual e seu temperamento eram masculinos, e a dotTech modificara seu corpo para transformá-lo no de um homem. Sua sexualidade, assim, é normatizada, e o que começa como um comportamento homossexual se torna heterossexual, se enquadrando no que costumamos aceitar como uma sexualidade "normal". Sem a dotTech, porém, seu corpo reverte para o feminino, ainda que de forma incompleta: ele aparentemente cria uma vagina, mas não cresce seios. Estabelece-se, assim, um corpo híbrido entre o masculino e o feminino, enquanto as atitudes e a imagem que Ae tem de si mesmo permanecem decididamente masculinos. Trata-se, então, de um corpo indefinido e de certa forma invisível, pois ele nunca nos é descrito com precisão. $\mathrm{O}$ corpo concreto e aparentemente fixo de Ae absorve, então, o princípio da incerteza que antes estava associado à dotTech, que agora aparece como um agente garantidor do controle.

A utopia de Stone, apesar de estar calcada na indefinição e no fluxo, apresenta-se, assim, como uma grande fantasia de controle: não só o controle do indivíduo sobre o próprio corpo, mas também de um controle invisível, porque internalizado, do corpo social sobre o indivíduo. A nanotecnologia funciona como uma imagem concretizada desse controle. Onipresente, ela vigia e regula tudo o que acontece - Ae, inclusive, imagina que ela pode ouvir suas conversas com a pedra. A harmonia da utopia de t'T é uma extrapolação da harmonia interna obtida através do controle do corpo. A eliminação do crime é também a eliminação do verdadeiramente transgressor, pois ela está apoiada na suavização de instintos primitivos relacionados a funções hormonais, na eliminação da dor e do desconforto, na descarga garantida de prazer, e na própria dificuldade de ferir ou matar um corpo praticamente invulnerável, impermeável às interferências desafiadoras do meio.

Nesse esquema de controle, porém, a dotTech não é soberana, ela é também vítima. Vivendo no mundo quântico, sua natureza é existir num estado de fluidez, de probabilidades que permanecem em suspenso. No entanto, essas probabilidades se concretizam em certezas por causa da interferência da vontade de seus hospedeiros, ou seja, das escolhas que eles fazem. A dotTech se configura como mais um corpo utópico, indefinido ao misturar o individual e o coletivo, invisível por estar escondida dentro de outros corpos com os quais se funde. Ela também busca o seu espaço utópico, o não-lugar da incerteza e do fluxo, que, para ser atingido, cobra um preço exorbitante: a morte da população de um planeta inteiro, de modo que a dotTech possa habitar corpos humanos vazios de vontade. Em Stone, a escolha é uma prisão. As escolhas feitas pelos seres humanos eliminam a liberdade da nanotecnologia que os habita. Para Ae, um ato de liberdade é abrir mão da identidade e do passado que poderiam defini-lo, escolhendo um novo nome formado pelas duas primeiras letras do alfabeto de sua cultura ("a" e "e"), de modo a esvaziar o ato da escolha: "I renounce all those names, and the person I was. I choose to be known by two letters instead of seven names, and I take the first two letters of the alphabet to avoid choice" (ROBERTS, 2002, p.22). Atinge-se, assim, o paradoxo, o verdadeiro não-lugar da utopia em Stone: a escolha é ao mesmo tempo uma não escolha.

Há algo de passivo nessa atitude, que, no caso de Ae, abre a possibilidade de manipulação externa por parte da dotTech. No entanto, aqui também se torna difícil adotar uma posição clara. Como em narrativas policiais tradicionais, em Stone também há o momento final da revelação, quando o mandante do crime é descoberto. É a própria dotTech que se dirige a Ae para descortinar sua participação como mandante do assassinato em massa e para explicar os motivos que a levaram a planejar esse crime - como costuma ocorrer com os detetives metafísicos, Ae se mostra mais uma vez passivo, já que não é ele na verdade quem descobre o culpado. No entanto, nas últimas páginas do romance, a dotTech entra em contato com ele novamente para revelar a razão de tê-lo escolhido como seu agente. É 
verdade que Ae seria o único capaz de cometer o assassinato, já que não havia outros criminosos na utopia; mais importante, porém, é o fato de ele ser semelhante à dotTech: ele também vive numa espécie de indefinição quântica. Como a dotTech diz a Ae: "You are not a good person, but neither are you a bad person. You are simultaneously a good and a bad person. At any given moment you are both things in an ethical wave-form of probabilities"' (ROBERTS, 2002, p.250). Há, assim, uma profunda identificação entre a dotTech e Ae. Ambos se confirmam na posição de corpo utópico, justamente pelo fato de (como as partículas subatômicas da física quântica,) ocuparem simultaneamente posições diferentes, às vezes opostas. Essa ideia de indefinição parece ser o principal princípio utópico do romance. A utopia, assim, seria marcada pela indefinição e pela ironia, já presentes no texto fundador de Thomas More. O caráter aberto desse princípio de indefinição parece uma resposta ao perigo de fechar a utopia num sistema imóvel e autoritário que, de acordo com Lyman Tower Sargent (2006, p. 12-13), seria um dos motivos pelos quais a utopia é vista com desconfiança nos dias de hoje. No entanto, esse mesmo caráter aberto levanta problemas éticos na narrativa de Stone. Afinal, se o ideal seria se manter perpetuamente em suspensão no que diz respeito a posições éticas e morais, como fazem Ae e a dotTech, como devemos interpretar a utopia apresentada no romance? Devemos aceitá-la como um ideal a ser seguido ou rejeitá-la como uma imagem distorcida e crítica da sociedade de consumo contemporânea? Qualquer escolha interpretativa implicaria uma tomada de posição que congelaria a utopia numa forma determinada. O que excluir quando tudo deve ser incluído? Stone, assim, desafia o pensamento utópico contemporâneo, ao acenar com a possibilidade sedutora da utopia, apenas para negar sua realização. Em vez de ser o não-lugar da estabilidade em que tensões sociais, emocionais e éticas são neutralizadas, a utopia passa a se caracterizar justamente por ser a posição impossível de uma tensão permanente. De acordo com Michael Holquist (1971, p.170), "a narrativa de detetive metafísica [...] não se preocupa em ter um final fechado em que todas as questões são resolvidas e depois podem ser esquecidas" (tradução livre). Embora Ae receba a sua explicação, e o leitor também, essa explicação não é capaz de trazer paz e conforto, como na estrutura da consolação descrita por Umberto Eco (1993, p.202). Ao contrário, a explicação suscita, a cada vez, novos questionamentos acerca do ser humano e dos limites do seu conhecimento, que transcendem a mera exploração do enredo de mistério em si, e permanecem sem solução.

\section{Nota}

1. O livro não existe; além disso, seu suposto autor, Kurt Soldan, não é um físico, e sim um músico que publicou partituras de vários compositores clássicos, como Handel, Mozart e Bach.

\section{Referências}

BAUMAN, Z. Utopia with No Topos. History of the Human Sciences, v. 16, n. 1, p. 11-25, 2003.

ECO, U. Apocalípticos e Integrados. São Paulo: Perspectiva, 1993.

FOUCAULT, M. Le Corps utopique. In: _. . Le Corps utopique suivi de Les Hétérotopies. s/c: Lignes, 2009. p. 7-20.

GOMEL, E. Mystery, Apocalypse and Utopia: The Case of the Ontological Detective Story. Science Fiction Studies, v. 22, n. 3, p. 343-56, 1995.

HAYCRAFT, H. Murder for Pleasure: The Life and Times of the Detective Story. Nova York: Appleton-Century, 1941.

HOLQUIST, M. Whodunit and Other Questions: Metaphysical Detective Stories in Post-War Fiction. New Literary History, v. 3, n. 1, Modernism and Postmodernism: Inquiries, Reflections, and Speculations, p. 135-156, 1971.

KLEIN, G. From the Images of Science to Science Fiction. In: PARRINDER, Patrick (org.). Learning from Other Worlds: Estrangement, Cognition, and the Politics of Science Fiction and Utopia. Durham: Duke UP, 2001. p. 119-126.

KRISTEVA, J. Approaching Abjection. In: Powers of Horror: An Essay on Abjection. Trad. Leon S. Roudiez. Nova York: Columbia UP, 1982. p. 1-31.

MARCUSE, H. Éros et civilization. Paris: Minuit, 2007. [1 $1^{\text {a }}$. ed. em francês de 1963.]

MERIVALE, P.; SWEENEY, S.E. (orgs.). Detecting Texts: The Metaphysical Detective Story from Poe to Postmodernism. Filadélfia: U of Pennsylvania P, 1999.

NATTI, T. The Text is Suspect: The Author, the Detective and the Subjective in Auster's City of Glass. 2004. 
118 André Cabral de Almeida Cardoso e Carla de Figueiredo Portilho, Os dilemas do indefinido: utopia, fluidez e ...

Disponível em http://www.crimeculture.com/ Contents/Articles-Spring05/Auster.html. Acesso em 01 novembro 2016.

ROBERTS, A. Stone. Londres: Gollancz, 2002.

"Stone". www.adamroberts.com. The latest news from author Adam Roberts. Disponível em http:// www.adamroberts.com/writing/stone. Acesso em 01 novembro 2016.

SARGENT, L. T. The Three Faces of Utopianism Revisited. Utopian Studies, v. 5, n. 1, p. 1-37, 1994.

In Defense of Utopia. Diogenes, v. 53, n. 11, p. 1117, fev. 2006.

SENNETT, R. The Culture of the New Capitalism. Edição Kindle. New Haven e Londres: Yale UP, 2006.

Recebido em: 11/11/2016 Aceito em: 10/02/2017 